DOI: $10.2478 /$ ausfm-2020-0004

\title{
The Ethical Anxiety of Remediation and Speculative Aesthetics in Landscape Film
}

\author{
Zoltán Szabó \\ University of Debrecen (Hungary) \\ E-mail: debaser1995@gmail.com
}

\begin{abstract}
The link between avant-garde cinema and painting has always been a conspicuous one but perhaps never as much as in the case of landscape films. However, not only repurposing or evoking specific paintings but constructing entire films with the intention of producing cinematic analogies to certain traditions of landscape painting presents a number of issues, especially when the films in question are inspired by the sensibilities of $19^{\text {th }}$ century Romanticism and explore similar topics, such as the works of Peter Hutton. The problem is essentially twofold: on the one hand, how to break away from the painterly roots and make an exclusively cinematic pictorial representation of landscape and, on the other hand, how to account for the complicit position of the filmmaker with regard to the nature-technology opposition they address. Within the theoretical framework of the recent speculative turn in philosophy and the implications of this with regard to aesthetics, I argue that an object-oriented approach to landscape filmmaking - as seen in the works of Chris Welsby -, by establishing pre-compositional rules within which landscape itself can intervene in the filmmaking process, provides a solution to both the aesthetic and the ethical anxiety that haunt landscape filmmakers.
\end{abstract}

Keywords: landscape film, landscape painting, environmental ethics, speculative aesthetics, post-humanism.

\section{Introduction}

In his proposal to the Canadian Film Development Corporation in 1969, Michael Snow writes that he wants "to make a gigantic landscape film equal in terms of film to the great landscape paintings of Cezanne, Poussin, Corot, Monet, Matisse and in Canada the Group of Seven" (1994a, 53). After he has realized this ambition in the form of The Central Region (La Région Centrale, 1971), he further elaborates in an interview how he got the idea for making the film: "the traditional painting 
division of subjects seems to me to be still applicable - portraiture, landscape, still life, etc. There are good reasons why those divisions are still used. It's like animal, vegetable, mineral - those things do exist. And I thought about how you could make a landscape film" (Snow 1994b, 78). The decision to bring landscape from the background to the foreground in cinematic representation and elevate it into a proper cinematic subject on its own right (just as it is in painting or, for that matter, in poetry), without it being subordinated to the demands of plot progression or character psychology, is an admittedly rare but by no means singular phenomenon.

As a matter of fact, this heightened attention to landscape as a space liberated from the constraints of storytelling, along with a return to certain traditions of landscape painting as a primary influence, coincides with the resurgence of independent and avant-garde cinema in the late 1960s and early 1970s. The particular style of landscape painting the films evoke and the artists they take inspiration from vary greatly for instance, Stan Brakhage's The Machine of Eden (1970) provides a cinematic analogy to Cézanne's post-impressionist landscapes, while Werner Nekes's tracking panorama shots in Makimono (1974) recall Chinese landscape scrolls. Nevertheless, the most enduring influence on this type of filmmaking, for a multitude of reasons, remain the works of $19^{\text {th }}$-century Romantic landscape painters, evident in Jon Jost's deep affinity with the Rocky Mountain School of painters in Canyon (1969), in the luminism of Larry Gottheim's Fog Line (1970), or in Peter Hutton's evocation of the Hudson River School in Study of a River (1997). Scott MacDonald delineates the roots of this shared interest between $19^{\text {th }}$-century artists and late $20^{\text {th }}$-century independent filmmakers. "For a good many filmmakers coming to maturity during those decades, a broad and penetrating cultural critique was essential. This critique was often directed at the commercialism of Hollywood, which was seen as a particularly visible index of the increasingly rampant materialism of capitalist culture. [...] For many filmmakers working outside the Industry and wanting to critique it, the fundamental question was how to develop a film practice that worked against the demands of the commercial and against this increasing tendency toward overload—and where to go for inspiration.” (MacDonald 2001a, 4.)

Furthermore, the re-emergence of landscape as a site of complex cultural discourse in cinema is not only a reaction to the function it had taken up by that point in mainstream cinema (a complement to narrative progression and character development), but also to its appropriation and reification as a tool of ideological interpellation. It is enough to recall Frederick James Turner's famous frontier thesis to see how closely (the image of) the American West is tied to the formation of certain values and principles, how westward expansion and the myths it has created 
have become inextricably intertwined with a set of characteristics which are seen as essential for the US: individualism, democracy, freedom, patriotism, etc. This ideological function of the frontier was not abandoned after the $19^{\text {th }}$ century but was taken up by cinema, especially by westerns - this really is, as André Bazin refers to it, the "American film par excellence" $(1971,140)$. James Benning's California Trilogy (2000-2002), for instance, provides a sustained deconstruction precisely of these myths by calling attention to how the formation of Southern Californian landscapes are a result of particular social institutions and class division.

Considering, therefore, how landscape imagery in mainstream cinema had, by the 1960s, become a mere story-space, completely subservient to narrative demands, and was seen almost exclusively through an ideologically pervaded camera lens, then the decision to return to $19^{\text {th }}$-century landscape painting and treat landscape as an autonomous cinematic subject by focusing on it for an extended period of time, divorced from the impositions of narrative and pointing to the external forces that almost imperceptibly transform and produce it, can be understood as a radical expression of the aforementioned anti-commercial aesthetic and countercultural attitude that independent filmmakers of the period were seeking. However, landscape filmmakers, by consciously entering into a pictorial dialogue with $19^{\text {th }}$ century Romantic landscape painters and reviving their heritage, carry a burden that their aesthetic predecessors did not. Ágnes Pethő refers to this indebtedness that results from "incorporating, refashioning other media while also relating to these other media [...] as a major authority that cinema has to come to terms with" as the "anxiety of remediation" $(2011,233)$. In this paper, I outline the ethical implications of remediating $19^{\text {th }}$-century Romantic landscape imagery and exploring its central theme of nature-technology opposition, and then, referring to the works of British landscape filmmaker Chris Welsby, I propose that this ethical deadlock be resolved by unshackling cinematic representations of landscape from their painterly roots.

\section{The Ethics of Landscape Cinema}

The simplicity of subject and the directness of its representation that Gottheim's Fog Line, Hutton's Time and Tide, and many other landscape films made in a similar vein present (the works of James Benning, Sharon Lockhart, etc.) is analogous to the early cinema of the Lumière brothers. MacDonald sees this link to their actualities in Fog Line's uninterrupted 10-minute shot of the titular fog gradually dissipating over a New York valley, filmed from a fixed camera position (2001a, 5-7), and in Peter Hutton's similarly long, static shots broken by moments of darkness, almost 
as if they were separate short films in themselves $(2013,22)$. There is, however, in landscape film, not only a connection specifically to the films of the Lumières, but to what Tom Gunning in his seminal essay refers to as the early "cinema of attractions" in general. His contention is that these early, non-narrative films construct a markedly different relationship with the spectator than the narrative films that were to follow them: they are exhibitionist rather than voyeuristic (Gunning 2006, 382). MacDonald propagates precisely this new position that landscape films are able to carve out for the spectator (requiring them to slow down, be more attentive to the subtleties of the landscape, recognize how cinema transforms its object through the mechanical reproduction of its image, etc.) as the requirement of an ecocinema. This would "provide new kinds of film experience that demonstrate an alternative to conventional media-spectatorship and help to nurture a more environmentally progressive mindset” (MacDonald 2013, 20). Of course, the early cinema of attractions broke its realistic illusion by having the actors look into the camera, while landscape films generally assert their non-illusionism in a manner that is typical of structural/ materialist filmmaking, by calling attention to their own process of production and artificiality. Fog Line, for example, has a faint shape in the upper part of the image that is simply a smudge on the camera lens, while the apparatus in The Central Region occasionally ends up filming its own shadow on the ground.

This interrelatedness of natural phenomena and technological processes is not only a specific theme of a number of landscape films, repeating the similar concerns of $19^{\text {th }}$-century Romantic landscape painters. Rather, the interaction of nature and technology serves as the basis for the genre as such. In his essay on landscape cinema, P. Adams Sitney locates the essence of landscape films in bringing together "the disjunctions and the meshings of the world and the temporality of the medium” (1993, 125). Maureen Turim similarly emphasizes the interwoven processes of nature and technology as an inevitable concern for the genre, claiming that "a technology, that of the camera apparatus, confronts nature, transforming it. The manner in which this confrontation of artist, machine and nature takes place is inscribed in the image traces which comprise the film. The culture/nature paradigm is therefore inherent in films studying landscape" $(1985,122)$.

Hutton's Time and Tide makes this parallel to the cinema of attractions - as well as his awareness of his own participation in the long history of the Hudson's pictorial representation - quite evident by having, as a cinematic preface, Down the Hudson (Frederick S. Armitage and A. E. Weed, 1903) played in its entirety before beginning his own voyage on the river. Going up and down the Hudson and into the New York harbour, Hutton's meditative pacing and the silent beauty of his 
rigorously framed shots quickly lull the viewer into a state of quiet contemplation. That being said, the serene images of nature, taken from the decks of tugboats and tankers or filmed through portholes, are punctuated by the sight of industrial sites, nuclear power plants, and smoking factories along the coast. The commercial importance of the river - already evident a 100 years earlier in Down the Hudson - has led to the incessant exploitation of the area's natural resources and to the Hudson's pollution. However, what complicates matters is that Hutton himself, though to a much lesser degree, contributes to this environmental damage and enjoys its benefits merely by being a filmmaker.

Comparing Thomas Cole's painting The Oxbow (1836) and Gottheim's Fog Line, MacDonald observes two crucial differences between the positions from which they can approach their subject. According to him, what separates their common concern for the depiction of the intersection of natural processes and technological development lies in the different historical positions of the artists and the medium they utilize. When Cole divided his painting between the cultivated lands on the right and the untamed wilderness on the left, positioning himself in the act of painting on the side of the latter, he could still reflect on the gradual transformation of nature by technology as a detached observer, as one who could keep his distance and remain outside of the processes he critically addresses. Gottheim, as well as Hutton and other landscape filmmakers, does not possess the same privilege for two specific reasons. The first one is that untouched nature itself, by the early 1970s, had become no more than an illusory, unattainable ideal: even what little remained and remains of it now "functions entirely within those technological systems developed to exploit it, including the 'system' of motion picture production" (MacDonald 2001a, 12.) In this sense, the appreciation of natural beauty in an age where it is almost nonexistent - or, at the very least, inevitably tainted and contaminated by technology - can be compared to Adorno's example of returning to tonal composition after Schoenberg's atonal revolution. After a radical historical break (atonal composition or, in our case, the disappearance and complete transformation of nature in the time between $19^{\text {th }}$-century landscape painting and late $20^{\text {th }}$-century landscape cinema), going back to the old ways (tonal composition or the appreciation of natural beauty) acquires a new meaning: it has "lost its innocence" by necessarily being mediated by this break and now functions "as its negation," so that it inevitably becomes "a nostalgic clinging to the past, something fake" (Žižek 2012, 193). And, indeed, the second reason is that the camera itself is a product of the very same technological advances that have put an end to wilderness and led to the increasing exploitation and domination of nature, thus, the apparatus remains "connected to the industrial 
revolution by an umbilical cord" (MacDonald 2001a, 12). Or, as Stephen Rust and Salma Monani put it in their introductory chapter to a collection of essays on ecocinema, "from production and distribution to consumption and recirculation, the cinematic experience is inescapably embedded in ecological webs" $(2013,2)$.

Filmmaking itself is a dirty industry since it involves photo-chemical processes that contribute to environmental damage. There are certain images in Hutton's Time and Tide which conspicuously read like an abrupt return of this repressed ethical anxiety. For example, a ship passes by in front of the porthole that the camera films through in an early shot, revealing the name on its side that reads Chemical Pioneer [Fig. 1] - a phrase that could just as well describe Hutton himself, "who uses a mechanical/chemical medium against the flow of commercial media and commercial life in general" (MacDonald 2013, 29). Another shot of the glowing neon GE letters of the General Electric sign can easily be mistaken for spelling the letter $\mathrm{H}$ : $\mathrm{H}$, of course, standing for Hutton [Fig. 2]. The connection that is made between General Electric and the filmmaker is quite distressing considering that the company had significantly contributed to the pollution of the river for decades and protested its proposed clean-up by the Environmental Protection Agency (MacDonald 2013, 27). Hutton, however, sees an essential fissure between humans and nature. An overhead shot of a ship breaking its trail through the frozen surface of the river and then the ice quickly closing the gap after the ship has passed at once recalls the transcendence of nature that is suggested in the proverb that inspired the film's title ("time and tide wait for no man") and expresses a hope that nature can heal itself, as it were, and the ecological footprints humans leave behind will eventually disappear. [Figs. 3-4.]

It is clear, then, that the materiality of film cannot be disregarded in landscape cinema but this "historical complicity of cinematic beauty and environmental damage” (2001b, 87), as MacDonald refers to it, means that the landscape filmmaker, unlike the landscape painter, is necessarily implicated in the very processes they appear to criticize. This, as we have seen, is very much recognized by Hutton, as well as by Benning, Gottheim, and others, who are all painfully aware of this inherent self-contradiction of their work. ${ }^{1}$ The question remains, however, whether there is anything to be done to circumvent this ethical issue at the heart of landscape cinema rather than merely admitting it. It is my contention that the films of Chris

1 "Benning is aware that, despite his counter-Hollywood aesthetic, he is, in some ways, complicit with the industry. Benning: 'I am also somebody who's demanding a service that's polluting the earth: filmmaking isn't a clean industry, so one can question my righteous view. We're all the enemy in this story. To make Deseret, I drove to Utah from California nine times."' (MacDonald 2001a, 442.) 
Welsby - which are conspicuously absent from the above-mentioned ecocinema book - provide a possible solution.

\section{From Landscape as Subject to Landscape as Agent}

Briefly returning once again to Snow's The Central Region, I believe it is essential that he emphasizes camera movement as "an unexplored potentially rich part of cinema" and the apparatus itself as "an instrument which has expressive possibilities in itself” (1993a, 53). I would argue that it is precisely Snow's structural/materialist approach to landscape imagery that opens up a space in which the aforementioned ethical deadlock can be resolved and, what is more, presents cinema's most important contribution to the historical development of the pictorial depiction of landscape by creating post-painterly landscape imagery. Filming a barren landscape in the northern wilderness of Canada, Snow not only eliminated any traces of human presence and activities in front of the camera but, what is even more crucial, removed himself from the filming process by having had constructed an elaborate tripod which could move according to pre-determined programming or with the help of a remote control. The machine was free to move horizontally and vertically with different speeds, while the camera mounted on it could rotate around its axis. However, the full implications of this method of landscape filmmaking, utilizing the expressive potentials of the camera, were only subsequently explored by the British filmmaker Chris Welsby. The crucial difference between Snow's The Central Region and Welsby's works is that the latter's a priori compositional rules do not only reduce the filmmaker's direct influence on the image-capturing process but also, when applied, extend his creative agency to the cinematic subject.

This is perhaps best illustrated by two of his films where the changing movement of the wind is utilized as an organizing principle for the film's form. In Wind Vane (1972), the titular objects are attached to two cameras that are mounted on tripods. Since the cameras are completely free to pan horizontally, the way they end up recording images of the landscape is determined by the varying strength and direction of the wind. Windmill II (1973) similarly relies on the shifting speed and direction of the wind. In it, the camera films a park landscape through the blades of a small windmill. Since the blades are covered in a mirrored fabric, the recorded footage varies between the landscape seen through the blades and the camera's own image reflected in them depending on the changing qualities of the wind. If there is no wind and the windmill does not move, we see the landscape behind it, and if there is wind and the windmill's blades rotate with enough speed, then we see the 
camera's reflection in them. More than a mere self-reflexive gesture that is meant to assert the materiality of the representational process as opposed to sustaining cinematic illusionism, calling attention to the apparatus and its transformative power with regard to the filmed landscape suggests Welsby's keen awareness of the complexities of nature-technology relationship and the peculiar position landscape films occupy between the two.

Although Sitney claims that "the mechanical function operating in Welsby's and Snow's landscape films resist [Stan Brakhage's] metaphoric humanization of the filmic apparatus, and by extension, the landscape it records" (1993, 123-24), I would argue that this is only true in the case of Snow's The Central Region. Welsby's cameraeye, on the contrary, remains just as much a camera-I as it is in the case of Brakhage, except that in Welsby's films it is not the filmmaker's "intense experience of seeing" that it conveys (Sitney 2002, 160); rather, it captures the gaze of the landscape itself. Especially in Wind Vane, the immediate association that the two-camera setup functioning almost as two eyes - elicits is that we see, in the film, nature looking and seeing itself through the camera. At first, this anthropomorphizing of nature might appear as a step back from Snow's purely mechanical vision of the landscape. Somewhat counterintuitively, though, it might be precisely a certain degree of anthropomorphism that is needed to avoid the kind of anthropocentrism that puts a fissure between humans and the environment they are inextricably embedded in. According to Jane Bennett, "maybe it is worth running the risks associated with anthropomorphizing (superstition, the divinization of nature, romanticism) because it, oddly enough, works against anthropocentrism: a chord is struck between person and thing, and I am no longer above or outside a nonhuman 'environment.' Too often the philosophical rejection of anthropomorphism is bound up with a hubristic demand that only humans and God can bear any traces of creative agency" (2010, 120). We can see in this parallel concern between Welsby and Bennett one of the many ways in which the former's works appear to prefigure the recent speculative turn in continental philosophy. The cinema of Welsby implicitly and the writings of certain speculative materialists explicitly propagate an object-oriented approach to nature, one that believes that all objects (human and non-human entities) of the world subsist on the same ontological plane, standing in a non-hierarchical, reciprocal relationship to each other, affect and are affected in a multitude of ways. Ben Woodard turns his attention specifically to the relationship between nature and aesthetics in Uncomfortable Aesthetics (2014), asking what an ecologically focused speculative aesthetics would look like. According to him, the immediately obvious answer would be either to "reinstate the Kantian sublime but orient it 
towards transcendental realism by moving the split of sense regarding space from the subject to the object" or to "restructure our interaction with nature in order to seriously reconsider all material production as having a real irreparable cost" (2014, 107-108). Having said that, neither of the two are viable approaches in his view, considering that the former strategy is "preempted aesthetically by the fantasies of eco-catastro-porn," while the latter, "by urging superficial changes to consumption practise, aims to make capitalism compatible with ecology" (Woodard 2014, 108). Turning to Schelling's nature writings in search of an alternative approach, Woodard concludes that "ecology requires an aesthetics of manipulation that emphasizes the razorblades of contingency" in order to "capture at once nature's forming of us and our forming of nature" $(2014,110-111)$. Incidentally, I believe this is precisely what Welsby's films, unbeknownst to Woodard, manage to achieve.

Let us now turn our attention to another one of his works, Park Film (1972), which, by introducing human presence and activity into his usual pre-compositional frame, renders this reciprocal and non-hierarchical determination between human and nonhuman elements visible, and by doing so, I claim, illustrates how an object-oriented approach makes landscape imagery enter into a post-painterly phase in landscape cinema as well as circumvents the ethical anxiety that pervades the genre. In this film, the camera, which is pointed at a busy park pathway, takes a frame each time a person enters the picture and each time a person moves out of the picture. The frequency with which the camera triggers its shutter - in other words, the temporal sequences or the pace of the film - is therefore determined by the movement of the people through the park. Their flow dictates the speed with which clouds, shadows and everything else moves in the image, but the flow of the people is, in turn, also dependent on such external factors as the weather, what time of the day it is, rush hours, etc. The point is not to enter the risky territory of panpsychism and assume that even non-human entities possess some form of consciousness but rather to cinematically engage in what Levy R. Bryant refers to as alien phenomenology; that is, to make an attempt to "suspend our own human ways of operating and encountering the world so as to investigate non-human ways of encountering the world" $(2014,63)$. Welsby's Park Film in particular, to use Bryant's terminology, allows us to witness the ways in which humans, nature, and the camera apparatus are structurally open to each other, the kinds of flows each of them respond to and the unique operations they carry out to transform these flows.

As far as the two prominent aesthetic sensibilities are concerned that pervade romantic pictorial representation, the beautiful and the sublime, Hutton's Time and Tide firmly occupies the position of the former with its tranquil pacing and 
contemplative gaze. Drawing on Barbara Novak's distinction between the two approaches to $19^{\text {th }}$-century landscape painting - the "grand opera" and the "still small voice," which are roughly parallel to the Kantian categories of the beautiful and the sublime -, MacDonald compares Hutton's serene and atmospheric landscapes with the works of Luminist painters, which reflect and offer "a more meditative route to the spiritual than that provided by the awesome paintings of Church, Bierstadt, and Moran" (2001b, 68). Contrary to this, Welsby's films clearly evoke a sense of sublimity but neither by attempting to represent sublime objects in the grand operatic style nor in the way that Woodard rightly rejects as being a dead-end for an ecologically sensitive speculative aesthetics. Rather, in line with how Lyotard characterizes the modern sublime in $20^{\text {th }}$-century avant-garde, they are "sublime in the sense that Burke and Kant described and yet it isn't their sublime any more" (1991b, 93).

The modern sublime of minimalist and abstract art that Lyotard proposes is something whose seeds are already present in the Kantian aesthetics of the sublime, specifically in what he calls negative representation or non-representation (1991b, 98). However, contrary to the romantic attempts to represent sublime objects, he sees the task of the avant-garde precisely in representing the unpresentable itself. ${ }^{2}$ The way Lyotard describes the modern sublime at work in Newman's paintings also reveals the manner in which Welsby's post-romantic films allude to something ineffable, evoking the unpresentable through their form: "when he seeks sublimity in the here-and-now he breaks with the eloquence of romantic art but he does not reject its fundamental task, that of bearing pictorial or otherwise expressive witness to the inexpressible. The inexpressible does not reside in an over there, in another word, or another time, but in this: in that (something) happens. In the determination of pictorial art, the indeterminate, the 'it happens' is the paint, the picture. The paint, the picture as occurrence or event, is not expressible, and it is to this that it has to witness" (1991b, 91-92). Later on, Lyotard writes that "with the advent of the aesthetics of the sublime, the stake of art in the nineteenth and twentieth centuries was to be the witness to the fact that there is indeterminacy" (1991b, 101). While the paintings of Newman, Pollock, Rothko and others do so through the abandonment of classical and baroque figuration, Welsby achieves this by inscribing this indeterminacy in the form of the films themselves to approximate

2 Nevertheless, there is a clear link between $19^{\text {th }}$-century Romanticism and $20^{\text {th }}$-century Abstract Expressionism. Years before Lyotard, the Romantic heritage of the non-representational school of New York painters was already recognized by Robert Rosenblum in his article entitled The Abstract Sublime, while Barbara Novak also saw a clear connection between $19^{\text {th }}$-century landscape painting and Abstract Expressionism (Gustafsson 2007, 68). 
an inexpressible real at their core. Unlike Hutton's Time and Tide, Welsby's films can thus be said to offer, by rendering visible the invisible through its formal indeterminacy, "a way out of romantic nostalgia because they do not try to find the unpresentable at a great distance, as a lost origin or end, to be represented in the subject of the picture, but in what is closest, in the very matter of artistic work" (Lyotard 1991a, 126).

Although, as we have seen before, landscape film can be considered as a return to the early, non-narrative and exhibitionist cinema of attractions, Welsby's films construct a certain narrativity that Peter Wollen praises precisely for bridging the gap between non-narrative avant-garde cinema and narrative cinema: "the British landscape film-makers often use a new type of narrativity, in which both filmmaker and 'nature' as causal agent play the role of protagonist. A pro-filmic event, which is a conventional signified ('landscape'), intervenes in the process of filming, determining operations on the 'specifically cinematic' codes" (Wollen 1976, 86). Welsby's unusual understanding of the interrelatedness of nature and technology is already evident in the definition he gives of landscape in an interview. "I see landscape as part of what we call nature, which is everything that cannot be included in the definition of mind. And nature would include, on this definition, all of technology too. [...] Landscape is a subdivision of nature as a whole. The degree to which we call it landscape is the degree to which mind has had an effect on it, the degree to which it is structured and modified by ideas and concepts. [...] Technology and landscape are both part of nature.” (Welsby 2003, 125.) Although this characterization, as Henrik Gustafsson points out, "seems to circumvent the fact that 'nature' is a charged cultural construct on its own" $(2007,16)$, it nevertheless clearly indicates the position from which he can reconceptualize the nature/culture binary and the role of (film) technology within it. The antagonism of nature and culture, and the inevitable disharmony rapid technological development introduces between the two and whether it can be in any way reconciled was, of course, perhaps the most frequently explored topic among landscape painters in the wake of the second industrial revolution. The depiction of railways and steam locomotives - possibly the most symbolic images of the era - are very much ambiguous in, for instance, Thomas Cole's River in the Catskills (1842) and in George Innes's The Lackawanna Valley (1855). Both paintings are susceptible to two contradictory interpretations: they can be seen either as affirming the irreconcilable tension between nature and civilization or as celebrating the harmony between the two. Furthermore, Cole's already-mentioned The Oxbow makes this ambiguity and uncertainty about the future even more visible in the way that the Connecticut River appears to form a 
question mark between the untamed wilderness on the left and the cultivated lands of civilization on the right.

Sitney points out that Welsby's definition of landscape is strangely Hegelian (1993, 124) and, likewise, his approach appears properly dialectical in rejecting the simple dualism of nature and technology, treating the question already as its own answer and initiating a shift of perspective, allowing a new subjective position to emerge. In his films, technology is no longer simply conceived in contrast to nature, as an instrument of exploitation, domination, and surveillance - rather, through a dialectical turn, the development and ubiquity of technology becomes a positive condition in that the unique capacities of the camera apparatus allow us to reconceptualize nature and our place in it. As Welsby extends his own creative agency as a filmmaker to his cinematic subject by establishing a specific precompositional framework within which the landscape can actively participate in the filmmaking process, the inherently colonizing and totalizing gaze of the camera is turned - at least to a certain extent - in the service of nature: his introduction of chance-based operations and indeterminacy in this manner transforms the filmmaking process from artistic exploitation based on a hierarchical relation into an act of collaboration between the filmmaker and his cinematic subject.

The expressive capacity of the camera that Snow emphasizes and is utilized through Welsby's pre-determined compositional rules is something that neither the brush of the landscape painter nor the pen of the landscape poet possesses. However, the indeterminate movement and operations of the recording device within a strictly defined compositional frame is reminiscent of musical compositions which are, in some way or another, indeterminate with respect to their performance. Using Johann Sebastian Bach's The Art of the Fugue as an example, where the timbre and amplitude of the material is not given, John Cage compares the function of the performer to "that of someone filling in color where outlines are given" (1973, 35). The landscape takes on an analogous function in Welsby's films, where the strict outlines are provided by his a priori compositional frame and nature takes on the role of the performer, filling it in with colour, as it were. The dynamic and reciprocal interactions between nature and technology are thus no longer an implicit presupposition of the genre or a subject of representation but come to be performed through the very form of the film. It is in this way, I would argue, that landscape cinema is able to transcend its painterly heritage, at once resolving the ethical deadlock that is present in films which rely on painterly traditions as well as instigating a radical break in the historical development of landscape imagery. In Chris Welsby's films and in the works of other (mainly British) landscape 
filmmakers who utilize similar structural/materialist approaches to their subject, William Henry Fox Talbot's early description of the camera as the pencil of nature appears more accurate than ever before.

\section{References}

Bazin, André. 1971. The Western, or the American Film par excellence. In What is Cinema? Volume II, ed. Hugh Gray, 140-48. Berkeley: University of California Press.

Bennett, Jane. 2010. Vibrant Matter: A Political Ecology of Things. Durham: Duke University Press.

Bryant, R. Levy. 2014. Onto-Cartography: An Ontology of Machines and Media. Edinburgh: Edinburgh University Press.

Cage, John. 1973 [1961]. Silence: Lectures and Writings. Hanover: University Press of New England.

Gunning, Tom. 2006. The Cinema of Attraction[s]: Early Film, Its Spectator and the Avant-Garde. In The Cinema of Attractions Reloaded, ed. Wanda Strauven, 381-388. Amsterdam: Amsterdam University Press.

Gustafsson, Henrik. 2007. Out of Site: Landscape and Cultural Reflexivity in New Hollywood Cinema 1969-1974. Stockholm: Almqvist \& Wiksell International.

Lyotard, Jean-Francois. 1991a. Representation, Presentation, Unpresentable. In The Inhuman: Reflections on Time, 119-128. Stanford: Stanford University Press.

Lyotard, Jean-Francois. 1991b. The Sublime and the Avant-Garde. In The Inhuman: Reflections on Time, 89-107. Stanford: Stanford University Press.

MacDonald, Scott. 2001a. The Garden in the Machine: A Field Guide to Independent Films About Place. Berkeley: University of California Press.

MacDonald, Scott. 2001b. Peter Hutton: The Filmmaker as Luminist. Chicago Review vol. 47, no. 3 (Fall): 67-87.

MacDonald, Scott. 2013. The Ecocinema Experience. In Ecocinema Theory and Practice, eds. Stephen Rust, Salma Monani and Sean Cubitt, 17-42. New York: Routledge.

Pethő, Ágnes. 2011. Cinema and Intermediality: The Passion for the In-Between. Newcastle upon Tyne: Cambridge Scholars Publishing.

Rust, Stephen and Salma Monani. 2013. Introduction: Cuts to Dissolves - Defining and Situating Ecocinema Studies. In Ecocinema Theory and Practice, eds. Stephen Rust, Salma Monani and Sean Cubitt, 1-13. New York: Routledge. 
Sitney, P. Adams. 1993. Landscape in the Cinema: The Rhythms of the World and the Camera. In Landscape, Natural Beauty and the Arts, eds. Salim Kemal and Ivan Gaskell, 103-126. Cambridge: Cambridge University Press.

Sitney, P. Adams. 2002. Visionary Film: The American Avant-Garde 1943-2000. Oxford: Oxford University Press.

Snow, Michael. 1994a. La Région Centrale. In The Collected Writings of Michael Snow, 53-56. Waterloo: Wilfried Laurier University Press.

Snow, Michael. 1994b. The Life \& Times of Michael Snow. In The Collected Writings of Michael Snow, 68-80. Waterloo: Wilfried Laurier University Press.

Turim, Maureen Cheryn. 1985 [1978]. Abstraction in Avant-Garde Films. Ann Arbor: UMI Research Press.

Welsby, Chris. 2003. Interview with Chris Welsby. In Undercut Reader: Critical Writings on Artists' Film and Video, eds. Nina Danino and Michael Maziére, 121-125. London: Wallflower Press.

Wollen, Peter. 1976. The Two Avant-Gardes. In Edinburgh '76 Magazine, Number 1: Psycho-analysis/Cinema/Avant-Garde, eds. Phil Hardy et al., 77-86. Edinburgh: Edinburgh Film Festival.

Woodard, Ben. 2014. Uncomfortable Aesthetics. In Speculative Aesthetics, ed. Robin Mackay, James Trafford, Luke Pendrell, 107-111. Falmouth: Urbanomic Media Ltd.

Žižek, Slavoj. 2012. Less Than Nothing. London: Verso.

\section{List of Figures}

Figures 1-2. Peter Hutton: Time and Tide (2003), possible self-references of the author.
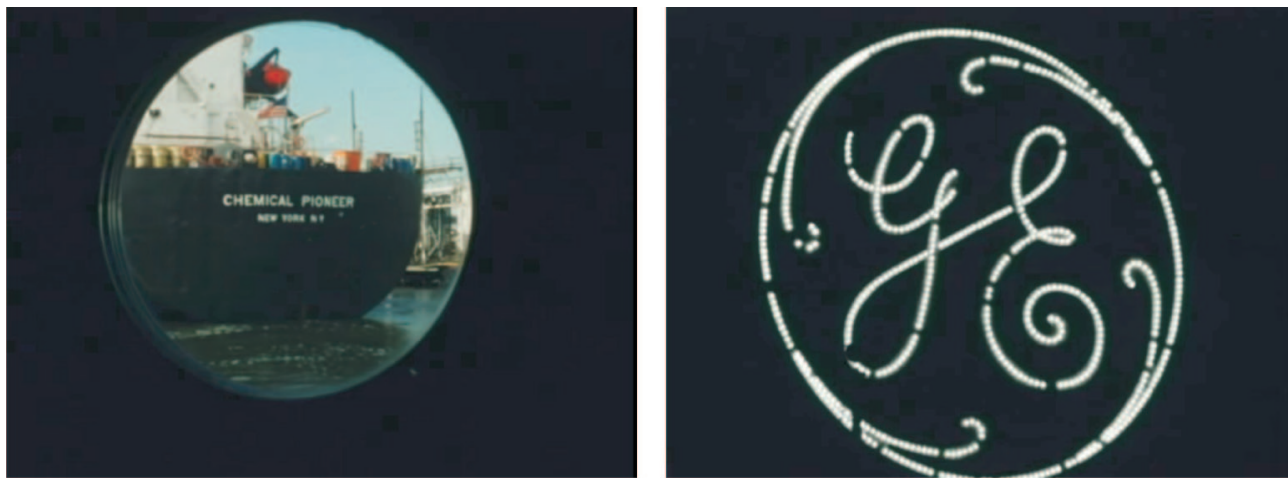
Figures 3-4. The ice heals itself after the ship has broken its path through it in Time and Tide.
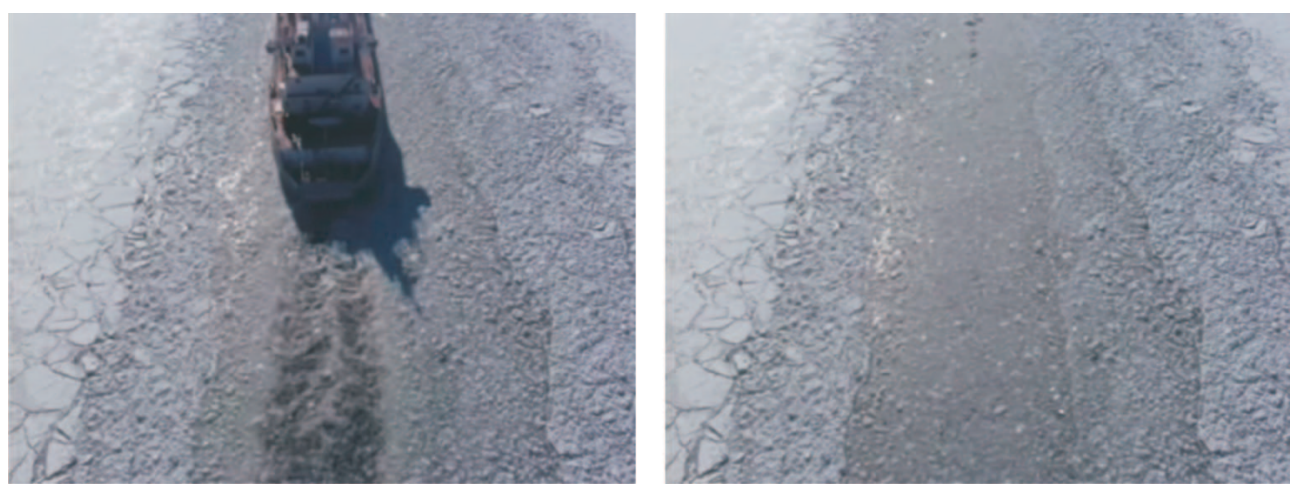